\title{
The Effects of Incentive Framing on Performance Decrements for Large Monetary Outcomes: Behavioral and Neural Mechanisms
}

\author{
Vikram S. Chib, , ${ }^{1,2,3,4}$ Shinsuke Shimojo, ${ }^{3,4}$ and John P. O’Doherty ${ }^{4,5}$ \\ ${ }^{1}$ Department of Biomedical Engineering, Johns Hopkins University School of Medicine and ${ }^{2}$ Kennedy Krieger Institute, Baltimore, Maryland 21205, \\ ${ }^{3}$ Division of Biology and Biological Engineering, ${ }^{4}$ Computation and Neural Systems, and ${ }^{5}$ Division of Humanities and Social Sciences, California Institute of \\ Technology, Pasadena, California 91125
}

There is a nuanced interplay between the provision of monetary incentives and behavioral performance. Individuals' performance typically increases with increasing incentives only up to a point, after which larger incentives may result in decreases in performance, a phenomenon known as "choking." We investigated the influence of incentive framing on choking effects in humans: in one condition, participants performed a skilled motor task to obtain potential monetary gains; in another, participants performed the same task to avoid losing a monetary amount. In both the gain and loss frame, the degree of participants' behavioral loss aversion was correlated with their susceptibility to choking effects. However, the effects were markedly different in the gain and loss frames: individuals with higher loss aversion were susceptible to choking for large prospective gains and not susceptible to choking for large prospective losses, whereas individuals with low loss aversion choked for large prospective losses but not for large prospective gains. Activity in the ventral striatum was predictive of performance decrements in both the gain and loss frames. Moreover, a mediation analysis revealed that behavioral loss aversion hindered performance via the influence of ventral striatal activity on motor performance. Our findings indicate that the framing of an incentive has a profound effect on an individual's susceptibility to choking effects, which is contingent on their loss aversion. Furthermore, we demonstrate that the ventral striatum serves as an interface between incentive-driven motivation and instrumental action, regardless of whether incentives are framed in terms of potential losses or gains.

Key words: gain; loss; motor; reward; ventral striatum

\section{Introduction}

Recent studies have observed that a pernicious interplay exists between increased potential monetary gains and performance: when executing skilled tasks, individuals' performance increases as the level of monetary incentive increases only up to a point, after which greater incentives become detrimental to performance (Ariely et al., 2009; Chib et al., 2012). Psychological literature refers to these performance decreases as a form of "choking under pressure” (Baumeister, 1984; Beilock and Carr, 2001).

In a previous functional magnetic resonance imaging (fMRI) study (Chib et al., 2012), we found that activity in the ventral striatum increased with the magnitude of reward offered at the

Received April 12, 2014; revised Aug. 28, 2014; accepted Sept. 20, 2014.

Author contributions: V.S.C., S.S., and J.P.O. designed research; V.S.C. performed research; V.S.C. analyzed data; V.S.C., S.S., and J.P.O. wrote the paper.

This work was funded by National Science Foundation Grant 1062703 (J.0.D.), the Gordon and Betty Moore Foundation (J.0.D.), grants from the Japan Science and Technology Agency/Core Research for Evolutional Science and Technology (S.S.), and the California Institute of Technology/Tamagawa Global Center of Excellence (S.S. and J.0.D.). We thank Daniel McNamee and Simon Dunne for helpful discussions and insights and Ralph Lee for his assistance.

The authors declare no competing financial interests.

Correspondence should be addressed to Vikram S. Chib, 707 North Broadway, G04, Baltimore, MD 21205. E-mail: vchib@jhu.edu.

DOI:10.1523/JNEUROSCI.1491-14.2014

Copyright $\odot 2014$ the authors $\quad 0270-6474 / 14 / 3414833-12 \$ 15.00 / 0$ trial onset but decreased with increasing incentives during performance of a skilled motor task. The extent of subjects' ventral striatal deactivations at the time of task performance was positively correlated with their susceptibly to choking for large incentives. Both neural responses at the time of task performance and susceptibility to choking were predicted by an independent measure of an individual's behavioral loss aversion (i.e., a measure of how strongly one prefers avoiding losses to acquiring gains).

These findings motivated two hypotheses about how choking is mediated at the behavioral and neural levels. First, evaluation of the prospect of failing at a task and thus not receiving (losing) the available incentive may be especially important in leading to behavioral manifestations of choking. Second, the switch in activity in the ventral striatum reflects a role for this structure in representing a switch in reference point from a gain frame ("How much can I win?") during incentive presentation to a loss frame ("How much can I possibly lose?") during task performance.

To test these hypotheses, participants performed a highly skilled motor task similar to our previous study (Fig. 1; Chib et al., 2012). However, in this case, we compared performance under two conditions, both contingent on successful performance: (1) a loss condition involving working to avoid losing money; and (2) a gain condition involving working to win money. Given our hypotheses, a natural prediction for the loss condition is that 


\section{Gain Trials}

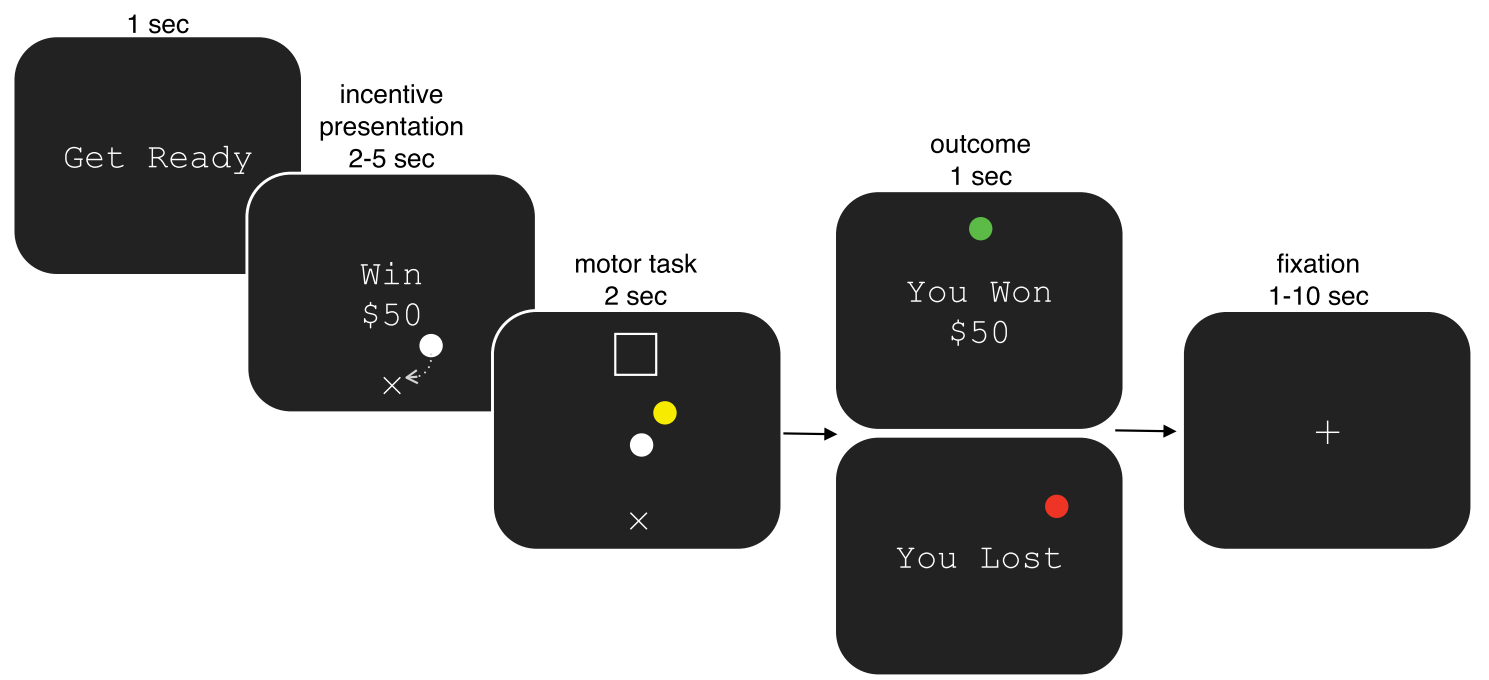

\section{Loss Trials}

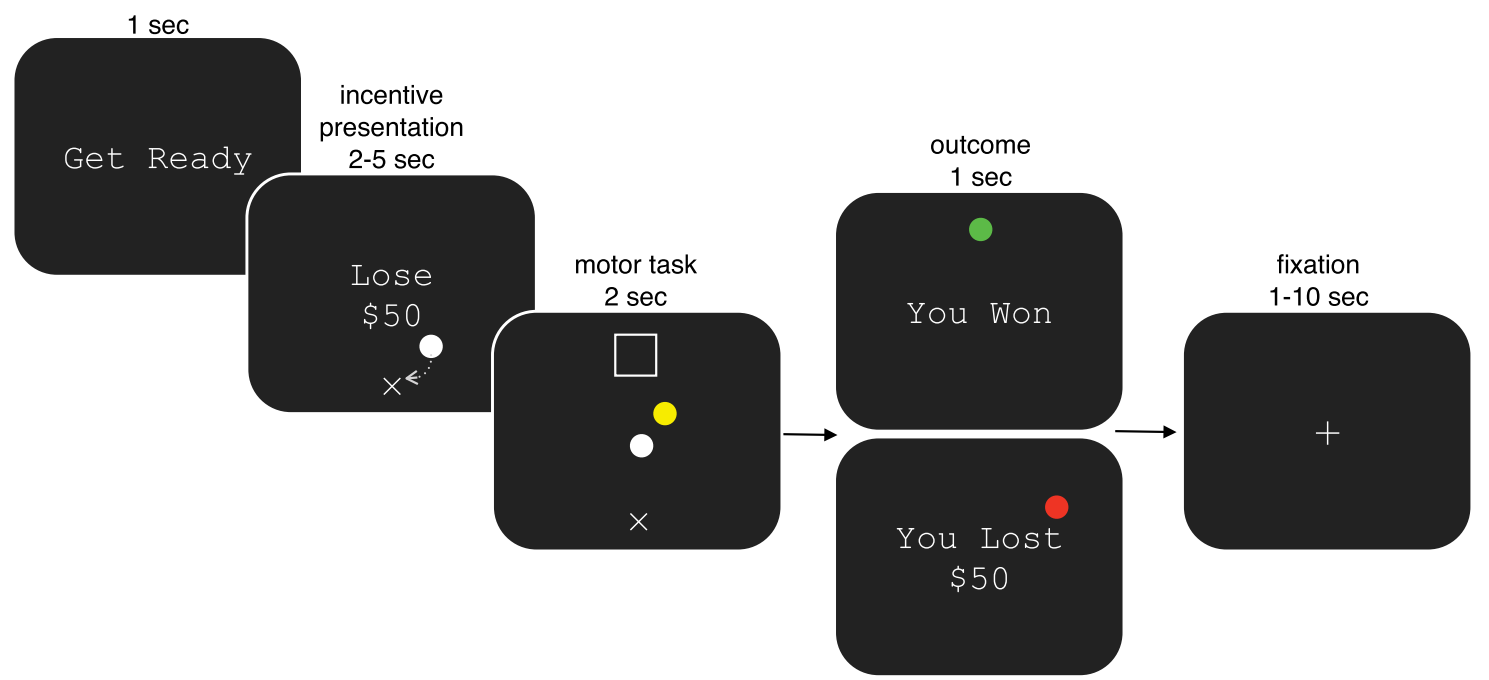

Figure 1. The incentive-based motor task. At the beginning of each trial, participants were presented with the incentive (e.g., Win $\$ 50$, Lose $\$ 50)$ for which they were playing. During incentive presentation, to initiate the motor task, participants placed their white hand cursor in the start position $(\times)$ for a random amount of time ( $2-5 \mathrm{~s}$ ). During the task, a target ( $\square$ ) appeared that was registered to a position $20 \mathrm{~cm}$ distal from the start. To successfully achieve the task, participants had to place their hand cursor and a mass cursor into the target within $2 \mathrm{~s}$, while achieving a final velocity $<0.02 \mathrm{~m} / \mathrm{s}$. At the end of the trial, they were shown a message indicating the outcome of their performance (e.g., "You Won" or "You Lost"). For gain trials, participants were to successfully perform the task for the possibility of winning an amount of money; if they were unsuccessful, they lost nothing. For loss trials, participants were to successfully achieve the task to avoid losing an amount of money; if they were unsuccessful, there was the possibility they would lose the amount presented on that trial. In the case that a participant successfully placed the spring mass in the target, a positive message was displayed ("You Won $\$ 50$ " or "You Won"); otherwise, the participant was informed of her negative outcome ("You Lost" or "You Lost $\$ 50 "$ ).

individuals would switch in the opposite direction to that found in our previous study: moving from a loss frame during cue presentation to a gain frame during task execution. Because participants would be evaluating prospective gains instead of losses during task execution, this could result in less susceptibility to choking in individuals who are of high loss aversion. At the neural level, the reference point switching hypothesis for ventral striatum would predict opposite effects in the ventral striatum during the loss condition compared with the gain condition: a decrease in activity correlating with incentive during presentation of the initial prospective loss, followed by an incentive-correlated increase in activity during task execution. Evidence of these effects at both the behavioral and neural levels would support the hypothesis that choking depends on the engagement of aversive processes and that the ventral striatum mediates such effects by representing reference-dependent prospective outcomes either in terms of potential gains or potential losses.

\section{Materials and Methods}

\section{Experimental setup}

Stimulus presentation and behavioral data acquisition were implemented using custom designed MATLAB (MathWorks) and C ++ programs implementing the OpenGL (Silicon Graphics) graphics libraries. During fMRI, visual feedback of targets and hand position were presented via a projector positioned at the back of the scanning room. Participants viewed a reflection of the projector image $(800 \times 600$ pixels $)$ in a mirror attached to the scanner head coil. This system allowed us to generate virtual images and manipulate visual feedback.

Direct views of participants' arms were obscured because they were positioned in the scanner head first supine, and the display mirror blocked their view. A Vicon motion tracking system (MX Ultranet sys- 
tem, with 4 MX40 + cameras; Oxford Metrics) was used to record the motion of an infrared reflective maker attached to the right index finger. During experiments, these signals were sent to our custom-designed software for real-time visual feedback of participants' hand position. The position signals were also recorded for additional offline analysis. Participants' arm movements were confined to the coronal plane, and visual feedback of these movements was presented in $2 \mathrm{D}$ on the visual display.

\section{Experimental procedures}

Participants. All participants were right handed and were prescreened to exclude those with a previous history of neurological or psychiatric illness. The California Institute of Technology Institutional Review Board approved this study, and all participants gave informed consent.

Twenty-six participants (mean age, 25 years; age range, 20-30 years; 11 females) took part in the experiment. Of these participants three were excluded because of highly imprecise estimation of prospect theory parameters. Note that a portion of these data, pertaining to only the monetary gain condition for a subset of participants $(n=16)$, was reported previously in the supplemental materials of Chib et al. (2012). Thus, the results from the gain condition alone cannot be considered a completely independent replication of the results reported in the supplemental materials of Chib et al. (2012) but rather are an extension (with additional participants) of those previously reported results. However, the results from the loss condition, the formal comparison between gain and loss frames, connectivity analyses, and mediation analyses reported in the present study are completely distinct from that reported in either the main text or the supplemental materials of that previous paper.

Motor task. The experiment comprised three phases that took place on 2 consecutive days. Participants performed the highly skilled motor task of controlling a virtual spring-mass system. This dynamic system was chosen because it was completely novel to participants and thus allowed us to evaluate performance uncorrupted by a participant's previous experiences or expertise. For a more detailed description of the spring-mass system, see the study by Chib et al. (2012). On the first day, participants practiced control of the spring-mass system (training phase). After the training phase, we determined participants' rates of success at various target sizes (thresholding phase). On the second day, participants controlled the spring-mass system with the purpose of avoiding losing money or to gain money (testing phase). Both the training and thresholding phases took place in a mock scanner to replicate the posture necessary in the scanning environment. The testing phase took place in the fMRI scanner. Before the experiment, participants were told they would receive a show-up fee of $\$ 40$ dollars at the end of experiment.

The training phase comprised 500 trials. A trial began when a participant put her hand cursor over the start position $(X)$ and ended after $2 \mathrm{~s}$. At the end of the trial, the cursors flashed green if the scoring criteria were met and red otherwise. The target size was $50^{2} \mathrm{~mm}$ throughout the training phase. The thresholding phase was the same as the training in all respects, except that it comprised 200 trials of varying sizes. Target sizes ranged from $10^{2}$ to $55^{2} \mathrm{~mm}$ in increments of $5^{2} \mathrm{~mm}$. Each target size was presented randomly 20 times. From these data, we obtained a psychometric curve that represented participants' performance over a range of target sizes.

Finally, during the testing phase, participants were scanned with fMRI while controlling the spring-mass system for reward. At the beginning of the testing phase, participants were given an endowment of $\$ 100$ in cash (this amount was separate from their show-up fee) and were told that, at the end of the experiment, one trial would be selected randomly and a payment made according to their performance on that trial. Participants were told that their $\$ 100$ endowment was given to them so that they could pay any eventual losses at the end of the experiment. This payout mechanism ensures that participants evaluate each trial independently. Participants performed trials for a range of incentives (i.e., $\pm \$ 0, \$ 25$, $\$ 50, \$ 75, \$ 100)$. Using psychometric curves generated during the thresholding phase, a target size was created for each participant such that it coincided with a $60 \%$ unincentivized success rate. Each incentive level was presented randomly 30 times for a total of 300 trials. At the beginning of each trial, participants were shown a message indicating the amount of incentive for which they were playing (e.g., Win/Lose $\$ 50$; jittered duration, $2-5 \mathrm{~s}$ ). They then performed the motor task, with the same success criteria as during training ( $2 \mathrm{~s}$ duration) and were shown the trial outcome ( $1 \mathrm{~s})$. At the end of each participants' testing phase, a single trial was selected at random and the participant was paid based on their performance on that trial.

Prospect theory task (measurement of loss aversion). This task was performed outside the fMRI scanner. Participants received an initial endowment of $\$ 25$ in cash (this amount was separate from their show-up fee and earnings from the testing phase) and were told that, at the end of the experiment, one trial would be selected randomly and a payment made according to their actual decision during the experiment. Participants were told that their $\$ 25$ endowment was given to them so that they could pay any eventual losses at the end of the experiment. Any net amount from the endowment that remained after subtracting a loss was theirs to keep, and similarly any eventual gain earned in the experiment was added to the initial endowment.

During the experiment, participants made choices among 140 different pairs of monetary gambles. Each pair contained a certain option involving a payout with $100 \%$ probability and a risky option involving gain and loss with equal probability. Participants had $4 \mathrm{~s}$ to make a choice, and they were penalized $\$ 1$ for every trial in which they did not respond in time. Specifics of the gambles used can be found in previous studies (Sokol-Hessner et al., 2009; Frydman et al., 2011). These gambles and task have been used in recent studies to obtain efficient measures of individuals' loss aversion parameters.

MRI protocol. A 3 Tesla Siemens Trio scanner and standard radio frequency coil were used for all the MR scanning sessions. To reduce the possibility of head movement-related artifact, participants' heads were positioned securely with foam position pillows. High-resolution structural images were collected using a standard MPRAGE pulse sequence, providing full brain coverage at a resolution of $1 \times 1 \times 1 \mathrm{~mm}$. Functional images were collected at an angle of $30^{\circ}$ from the anterior commissureposterior commissure (AC-PC) axis, which reduced signal dropout in the orbitofrontal cortex relative to the AC-PC-aligned images (Deichmann et al., 2003). Forty-five slices were acquired at a resolution of $3 \times$ $3 \times 3 \mathrm{~mm}$, providing whole-brain coverage. A one-shot echo-planar imaging (EPI) pulse sequence was used (TR, $2800 \mathrm{~ms}$; TE, $30 \mathrm{~ms}$; FOV, $100 \mathrm{~mm}$; flip angle, $80^{\circ}$ ).

\section{Data analysis}

Behavioral performance analysis. To account for differences in behavioral performance variance between participants (which contributed to extraneous variance in the aggregate data), we z-scored participants' performance measurements. To do this, each participants' measures of average performance were separately standardized (z-scored) across incentive categories.

Because of differences in participants' subjective value for monetary incentives, participants exhibited peak performance over the range of incentive levels; therefore, averaging performance at the presented incentive bins would attenuate the effect of peaked responses to incentives. To illustrate that group performance peaked and then dropped with increasing incentives, we classified the presented incentives as either being at the extremes of incentives or in the middle range of incentives. Rewards in the middle range of incentives were classified as those between $5 \%$ and $95 \%$ of the range of incentives [middle range of incentives, $(\$ 25, \$ 50$, $\$ 75)$ ], whereas rewards at the extremes of incentive were those outside this range [low extreme, $(\$ 0)$; high extreme, $(\$ 100)$ ].

We have previously used such behavioral normalization and classification procedures with similar incentivized-performance data and showed that such methods are unbiased (Chib et al., 2012).

Image analysis. The SPM8 software package was used to analyze the fMRI data (Wellcome Department of Imaging Neuroscience, Institute of Neurology, London, UK). A slice-timing correction was applied to the functional images to adjust for the fact that different slices within each image were acquired at slightly different points in time. Images were corrected for participant motion, spatially transformed to match a standard EPI template brain, and smoothed using a three-dimensional 
Gaussian kernel (6 mm FWHM) to account for anatomical differences between participants. This set of data was then analyzed statistically.

General linear model. The general linear model (GLM) was used to generate voxelwise statistical parametric maps from the fMRI data. We created participant-specific GLMs that included conditions at the time of incentive presentation and at the time of the motor task. We modeled two types of motor task conditions: trials in which participants were successful and unsuccessful. Each of these conditions were modeled separately for the gain and loss conditions. This resulted in a grand total of six modeled conditions. The incentive presentation events were modeled with a duration lasting the length of incentive presentation (2-5 s), whereas the motor task events were modeled with a fixed duration of $2 \mathrm{~s}$. For each condition, we introduced a parametric modulator corresponding to the incentive offered. In addition, regressors modeling the head motion as derived from the affine part of the realignment produced were included in the model.

With this model, we tested brain areas in which activity was correlated with incentive level at the time of incentive presentation and during the motor task. This was done by creating contrasts with the aforementioned parametric modulator for incentive at the times of incentive presentation and the motor task. To control for actual behavioral performance, motor task contrasts were computed for only those trials in which participants were successful.

Region of interest (ROI) analysis. We analyzed ventral striatal signals reported in Figure 3, $B$ and $C$, within an a priori anatomically defined ROI (encompassing nucleus accumbens and ventral parts of the putamen). This exact ROI was used in our previous study examining ventral striatal responses to monetary incentives (Chib et al., 2012). For this region, we regressed our design matrix on a representative time course, calculated as the first eigenvariate. This provides a very sensitive analysis because only a single regression is performed for this region and no multiple comparisons are required.

Psychophysiological interaction (PPI) analysis. To assess changes in connectivity between the ventral striatum and premotor cortex as a function of task performance and incentive offered, we performed a PPI analysis. PPI is a measure of context-dependent connectivity, which explains the activity of other brain regions in terms of the interaction between responses in a seed region and cognitive processes (Friston et al., 1997).

The PPI terms were generated by computing formal interactions between the physiological variables $(Y)$ and psychological variable $(P)$. The physiological variables $Y$ were the two blood-oxygen-level-dependent (BOLD) time courses taken separately from all voxels in $6 \mathrm{~mm}$ spheres surrounding the left (coordinates shown as $x, y, z ;-18,11,-8$ ) and right $(18,11,-8)$ peak coordinates in the ventral striatum seeds and deconvolved using a model of a canonical hemodynamic response function. These peak coordinates were obtained from a conjunction contrast between activations in the loss and gain conditions (Fig. 3A). To construct the psychological variable $P$, we calculated participants' average behavioral performance at each incentive level and on a trial-by-trial basis computed the interaction between average behavioral performance and the incentive offered $[P($ incentive $) \times$ incentive]. Separate psychological variables were created for gain and loss conditions. Using these physiological and psychological variables, we generated PPI regressors for the left and right ventral striatum separately for the loss and gain conditions.

We entered the physiological variable $Y$, the psychological variable $P$, the PPI interaction terms, and movement regressors into a new GLM. Importantly, this GLM also contained parametric incentive and average performance signals for all trials. Thus, any effects on the PPI would reveal coupling that could not be explained from the mutual correlation of the seed and target regions with incentive or performance values.

The contrast in Figure $5 \mathrm{~A}$ indicates regions of the brain that were correlated with the PPI regressors. Activity in this contrast shows regions of premotor cortex that had decreased functional connectivity with ventral striatum on trials in which incentives were large, in both the loss and gain conditions, and performance was diminished. The contrast reported in Figure $5 A$ was small-volume corrected, $p<0.05$, using coordinates extracted from a meta-analysis of fMRI studies examining motor activity (Mayka et al., 2006). Parameter estimates reported in the premotor cor- tex in Figure 5, $B$ and $C$, were extracted from all voxels within the aforementioned ROI.

Analysis of behavioral loss aversion. To estimate participants' loss aversion, we used a parametric analysis. We expressed participants' utility function $u$ for monetary values $x$ as follows:

$$
u(x)=\left\{\begin{array}{cc}
x & x \geq 0 \\
\lambda x & x<0
\end{array}\right.
$$

This formulation is similar to that introduced by Tverskey and Kahneman (1992), except we assumed that $u(x)$ was piecewise linear and risk neutral over the range of potential gains and losses presented to participants. These are assumptions that are used commonly for the range of gambles presented (Tom et al., 2007; Frydman et al., 2011). In this formulation, $\lambda$ represents the relative weighting of losses to gains. $\lambda>1$ indicates that losses loom larger than equal-sized gains.

Assuming that participants combine probabilities and utilities linearly, the expected utility of a mixed gamble can be written as $U(G, L)=$ $0.5 G+0.5 \lambda L$, where $G$ and $L$ are the respective gain and loss of a presented risky option. The expected utility of taking the certain option $S$ is given by $U(S)=S$. The probability that a participant chooses to make a gamble is given by the following softmax function:

$$
P(G, L, S)=\frac{1}{1+\exp (-\tau(U(G, L)-U(S)))},
$$

where $\tau$ is a temperature parameter representing the stochasticity of a participant's choice ( $\tau=0$ means that choices are random).

We used maximum likelihood to estimate parameters $\lambda$ and $\tau$ for each participant, using 140 trials gambles $(G, L, S)$ with participant response $y$ $\epsilon\{0,1\}$. Here $y=1$ indicates that the participant chose to make a gamble. This estimation was performed by maximizing the likelihood function using Nelder-Mead Simplex Method in MATLAB version 2013b:

$$
\sum_{k=1}^{512} y_{i} \log (P(G, L))+\left(1-y_{i}\right) \log (1-P(G, L)) .
$$

Median parameter estimates ( $n=23$ ) were $\lambda=1.41$ (interquartile range, 1.26) and $\tau=1.86$ (interquartile range, 0.76 ).

Mediation analysis. Mediation analysis is a specific case of structural equation modeling that refers to a situation that includes three or more variables, such that there is a causal process between all three variables (Judd and Kenny, 1981). In a mediation relationship, there is a direct effect between an independent variable and a dependent variable. There are also indirect effects between an independent variable and a mediator variable and between a mediator variable and a dependent variable. This formulation allows for a test of the strength of the direct effect between the independent and dependent variables, accounting for connections via a mediating variable. A measure of the direct effect (after controlling for the mediator) can be obtained using a series of regressions for all of the causal pathways and estimating a change in the direct effect.

We performed a mediation analyses of our data to test the possibility that relationships between loss aversion and task performance were mediated through responses in ventral striatum during motor performance. For these analyses, we performed between-participant regressions with variables for participants' behavioral loss aversion $\lambda$, the difference in neural sensitivity between losses and gains $S_{\text {loss }}-S_{\text {gain }}$, and the difference in performance at the highest incentive level between losses and gains, $P_{\text {loss }}^{\$ 100}-P_{\text {gain }}^{\$ 100}$. Model 1 was used to test our main mediation hypothesis, that $S_{\text {loss }}-S_{\text {gain }}$ mediates the relationship between $\lambda$ and $P_{\text {loss }}^{\$ 100}-P_{\text {gain }}^{\$ 100}$. Model 2 was a reverse mediation analysis that was performed to rule out the possibility of model misspecification. In Model 2, $P_{\text {loss }}^{\$ 100}-P_{\text {gain }}^{\$ 100}$ served as the mediator and $S_{\text {loss }}-S_{\text {gain }}$ as the dependent variable. The best-fitting model was considered to be the one with the smallest Akaike's information criterion (AIC). We used bias-corrected bootstrapping (a nonparametric sampling procedure) to test whether the specified mediator significantly mediated the relation between the independent and dependent variables. 

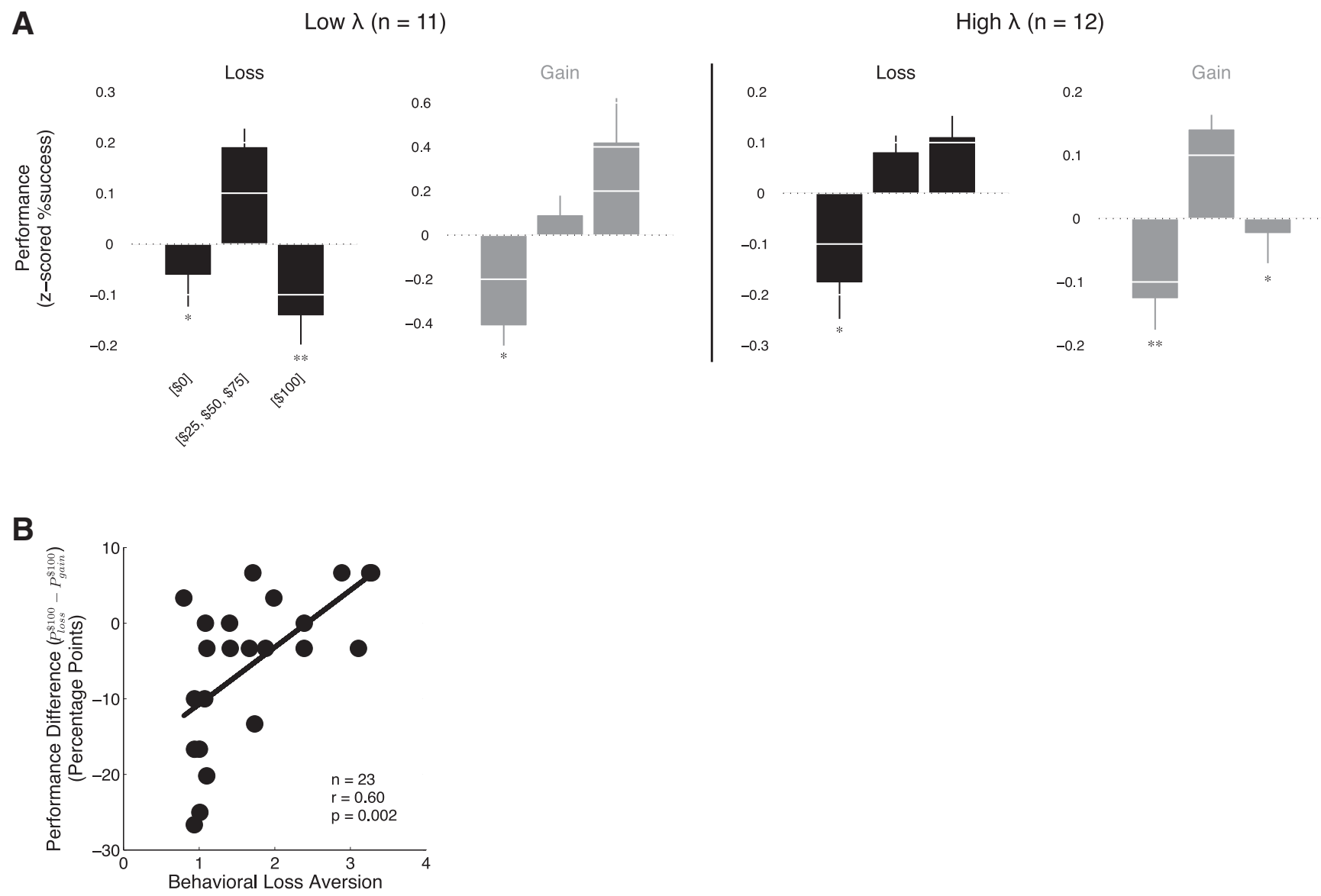

$(\lambda)$

Figure 2. Behavioral performance during scanning. $\boldsymbol{A}$, Grouping participants by the extent of their loss aversion (median split), we found that those with low loss aversion had decremented performance when presented with large potential losses and increased performance for increased potential gains. Conversely, those with high loss aversion had decremented performance when presented with large potential gains and increased performance for increased potential losses. The significance levels shown are for planned comparisons relative to performance at the middle range of incentives $\left({ }^{*} p<0.05 ;{ }^{* *} p<0.01\right)$. Error bars denote SEM. $B$, The correlation between behavioral loss aversion for each participant and their difference in performance between the $\$ 100$ loss and gain conditions.

\section{Results}

Behavioral responses for potential gains and losses

To test our prediction regarding participants' behavioral responses to incentive as modulated by the extent of their loss aversion, we grouped participants as having low loss aversion and high loss aversion (median split), and performed planned comparisons of their performance at the extremes of incentive with that in the middle range of incentive (Fig. 2A).

As reported previously (Chib et al., 2012), those participants that were of high loss aversion exhibited choking effects for large prospective gains compared with the middle level of incentive $\left.t_{(11)}=2.25, p<0.05\right)$, whereas those of low loss aversion did not show such effects, instead exhibiting increasing performance as a function of larger prospective gains $\left(F_{(2,30)}=12.12, p<0.005\right)$. As predicted by the reference-dependent hypothesis, we found that those participants who were of high loss aversion did not show choking effects as a function of increasing prospective losses in the loss condition $\left(t_{(11)}=0.14, p<0.89\right)$ and instead showed increasing performance $\left(F_{(2,33)}=4.17, p=0.51\right)$. Unexpectedly, we also found that participants who were of low loss aversion showed an increased susceptibility to choking effects in the loss condition $\left(t_{(10)}=3.18, p<0.01\right)$. Overall, participants that were very loss averse performed better when acting to avoid a loss, and those that were of low loss aversion performed better when acting to obtain a gain.
To examine participants' differential performance responses for large potential losses and gains over the continuum of behavioral loss aversion, we performed a between-participant regression of behavioral loss aversion and the difference between performance at the highest incentive levels $P_{\text {loss }}^{\$ 100}-P_{\text {gain }}^{\$ 100}(r=$ $0.60, p=0.002$; Fig. $2 B$ ).

We found that low loss aversion participants performed better for large potential gains compared with equal-magnitude potential losses and that high loss aversion participants performed better for large potential losses compared with equal-magnitude gains.

These behavioral results were in keeping with the switching reference-point hypothesis: in the loss condition, participants switch to evaluating prospective gains instead of losses during task execution, which results in less susceptibility to choking (for losses) in individuals who are of high loss aversion; in the gain condition, participants switch to evaluating prospective losses instead of gains during task execution, which results in more susceptibility to choking (for gains) in individuals who are of high loss aversion.

\section{Ventral striatal responses for potential gains and losses}

Because participants performed the incentivized motor task in the scanner, we were able to examine the neural responses to potential losses and gains during the initial presentation of incentive and during the execution of the motor task. We focused our 
Table 1. Regions with a significant increase in fMRI signal for increasing prospective gains at the time of incentive presentation $(p<0.001$, uncorrected)

\begin{tabular}{|c|c|c|c|c|c|}
\hline \multirow[b]{2}{*}{ Brain region } & \multirow[b]{2}{*}{ Laterality } & \multicolumn{3}{|c|}{$\begin{array}{l}\text { Peak Talairach } \\
\text { coordinates (mm) }\end{array}$} & \multirow{2}{*}{$\begin{array}{l}\text { Peak } \\
t \text { valu }\end{array}$} \\
\hline & & $x$ & $y$ & $z$ & \\
\hline $\begin{array}{l}\text { Striatum (nucleus accumbens, } \\
\text { ventral putamen)* }\end{array}$ & $\mathrm{R}$ & 12 & 14 & -11 & 6.43 \\
\hline $\begin{array}{l}\text { Striatum (nucleus accumbens, } \\
\text { ventral putamen)* }\end{array}$ & $\mathrm{L}$ & -15 & 8 & -11 & 5.99 \\
\hline Supplementary motor area* & $\mathrm{R}$ & 9 & 2 & 70 & 8.04 \\
\hline Thalamus* & $\mathrm{L}$ & 3 & -4 & 4 & 7.21 \\
\hline Parietal cortex* & $\mathrm{L}$ & -21 & -64 & 58 & 7.29 \\
\hline Posterior cingulate & $\mathrm{R}$ & 9 & -67 & 13 & 5.37 \\
\hline Occipital cortex & $\mathrm{L}$ & -12 & -70 & 10 & 5.93 \\
\hline Dorsolateral prefrontal cortex & $\mathrm{R}$ & 33 & 44 & 31 & 4.76 \\
\hline Dorsolateral prefrontal cortex & $\mathrm{L}$ & -33 & 38 & 40 & 5.11 \\
\hline Insula & $\mathrm{R}$ & 39 & 14 & -2 & 4.77 \\
\hline Anterior cingulate & $\mathrm{R}$ & 9 & 11 & 46 & 5.95 \\
\hline
\end{tabular}

At the time of incentive presentation, no regions showed decreasing activity for increasing prospective gains. Statistically significant activations are those found in a priori regions of interest (familywise error, ${ }^{*} p<0.05$ ) and those regions that survive whole-brain correction for multiple comparisons (at ${ }^{*} p<0.05$ ). Laterality - right (R); left (L); central (C).

Table 2. Regions with a significant increase in $\mathrm{fMRI}$ signal for increasing prospective losses at the time of incentive presentation $(p<0.001$, uncorrected)

\begin{tabular}{|c|c|c|c|c|c|}
\hline \multirow[b]{2}{*}{ Brain region } & \multirow[b]{2}{*}{ Laterality } & \multicolumn{3}{|c|}{$\begin{array}{l}\text { Peak Talairach } \\
\text { coordinates (mm) }\end{array}$} & \multirow{2}{*}{$\begin{array}{l}\text { Peak } \\
t \text { value }\end{array}$} \\
\hline & & $x$ & $y$ & $z$ & \\
\hline $\begin{array}{l}\text { Striatum (nucleus accumbens, } \\
\text { ventral putamen)* }\end{array}$ & R & 12 & 11 & -8 & 5.10 \\
\hline $\begin{array}{l}\text { Striatum (nucleus accumbens, } \\
\text { ventral putamen)* }\end{array}$ & L & -15 & 8 & -8 & 5.08 \\
\hline Caudate & L & -21 & -91 & 4 & 6.45 \\
\hline Supplementary motor area & $\mathrm{R}$ & 9 & 11 & 43 & 5.32 \\
\hline Insula & $\mathrm{L}$ & -54 & -37 & 22 & 4.94 \\
\hline Dorsolateral prefrontal cortex & $\mathrm{R}$ & 33 & 26 & 4 & 4.86 \\
\hline Cerebellum & $\mathrm{L}$ & -45 & -61 & -23 & 4.72 \\
\hline Parietal cortex & $\mathrm{R}$ & 60 & -40 & 40 & 4.67 \\
\hline Premotor cortex & $\mathrm{L}$ & -48 & -4 & 46 & 4.67 \\
\hline Midbrain & $c$ & 0 & -28 & -2 & 4.49 \\
\hline Posterior cingulate & $\mathrm{R}$ & 21 & -43 & 23 & 4.12 \\
\hline Temporal cortex & $\mathrm{R}$ & 42 & -58 & -17 & 4.05 \\
\hline
\end{tabular}

At the time of incentive presentation, no regions showed decreasing activity for increasing prospective losses. Statistically significant activations are those found in a priori regions of interest (familywise error, ${ }^{*} p<0.05$ ) and those regions that survive whole-brain correction for multiple comparisons (at ${ }^{*} p<0.05$ ). Laterality - right ( $R$ ); left (L); central (C).

analyses on the ventral striatum because we hypothesized (informed by previous experiments) (Knutson et al., 2001a,b; Chib et al., 2012) that this region would be involved in responding during both incentive presentation and motor performance. Additional regions showing activation outside of the ventral striatum are reported in Tables $1-4$.

Ventral striatal responses during incentive presentation

As reported previously, during the gain condition, at the time of incentive presentation, as prospective incentive levels for successful task performance increased, activity in the ventral striatum increased (Fig. $3 A, B$ ). However, contrary to our initial hypothesis of mirrored neural activity at the time of loss presentation, we did not observe a decrease in activity in the striatum as a function of increasing potential monetary losses in the loss condition (Fig. $3 A, B)$. Instead, activity increased with increasing prospective monetary losses in a manner similar to that observed during the gain condition $\left(F_{(4,88)}=29.67, p<0.0001\right)$. There was neither a significant effect of valance $\left(F_{(1,22)}=1.97, p=0.17\right)$ nor a signif-
Table 3. Regions with a significant decrease in fMRI signal for increasing prospective gains at the time of the motor task ( $p<0.001$, uncorrected)

\begin{tabular}{|c|c|c|c|c|c|}
\hline \multirow[b]{2}{*}{ Brain region } & \multirow[b]{2}{*}{ Laterality } & \multicolumn{3}{|c|}{$\begin{array}{l}\text { Peak Talairach } \\
\text { coordinates (mm) }\end{array}$} & \multirow{2}{*}{$\begin{array}{l}\text { Peak } \\
t \text { value }\end{array}$} \\
\hline & & $x$ & $y$ & $z$ & \\
\hline $\begin{array}{l}\text { Striatum (nucleus accumbens, } \\
\text { ventral putamen)* }\end{array}$ & $\mathrm{R}$ & 18 & 11 & -8 & 4.58 \\
\hline $\begin{array}{l}\text { Striatum (nucleus accumbens, } \\
\text { ventral putamen)* }\end{array}$ & $\mathrm{L}$ & -18 & 14 & -11 & 4.32 \\
\hline Occipital cortex & $\mathrm{R}$ & 30 & -85 & 19 & 5.55 \\
\hline Occipital cortex & $\mathrm{L}$ & -24 & -88 & 19 & 5.15 \\
\hline Parietal cortex & $\mathrm{R}$ & 63 & -19 & 37 & 5.05 \\
\hline Parietal cortex & $\mathrm{L}$ & -12 & -55 & 64 & 4.90 \\
\hline Supplementary motor cortex & $\mathrm{L}$ & -18 & -7 & 73 & 4.88 \\
\hline Globus pallidus & $\mathrm{R}$ & 24 & -13 & -2 & 4.67 \\
\hline Cingulate cortex & $\mathrm{L}$ & -6 & 5 & 46 & 4.61 \\
\hline Dorsolateral prefrontal cortex & $\mathrm{L}$ & -36 & 47 & 28 & 4.46 \\
\hline Primary motor cortex & $\mathrm{L}$ & 60 & -19 & 40 & 3.84 \\
\hline
\end{tabular}

At the time of the motor task, no regions showed increasing activity for increasing prospective gains. Statistically significant activations are those found in a priori regions of interest (familywise error, ${ }^{*} p<0.05$ ) and those region that survive whole-brain correction for multiple comparisons (at ${ }^{*} p<0.05$ ). Laterality-right (R); left (L); central (C).

Table 4. Regions with a significant decrease in $\mathrm{fMRI}$ signal for increasing prospective losses at the time of the motor task ( $p<0.001$, uncorrected)

\begin{tabular}{|c|c|c|c|c|c|}
\hline \multirow[b]{2}{*}{ Brain region } & \multirow[b]{2}{*}{ Laterality } & \multicolumn{3}{|c|}{$\begin{array}{l}\text { Peak Talairach } \\
\text { coordinates (mm) }\end{array}$} & \multirow{2}{*}{$\begin{array}{l}\text { Peak } \\
t \text { value }\end{array}$} \\
\hline & & $x$ & $y$ & $Z$ & \\
\hline $\begin{array}{l}\text { Striatum (nucleus accumbens, } \\
\text { ventral putamen)* }\end{array}$ & $\mathrm{R}$ & 12 & 8 & -11 & 3.60 \\
\hline $\begin{array}{l}\text { Striatum (nucleus accumbens, } \\
\text { ventral putamen)* }\end{array}$ & L & -18 & 8 & -8 & 3.54 \\
\hline
\end{tabular}

At the time of the motor task, no regions showed increasing activity for increasing prospective losses. Statistically significant activations are those found in a priori regions of interest (familywise error, ${ }^{*} p<0.05$ ) and those region that survive whole-brain correction for multiple comparisons (at ${ }^{*} p<0.05$ ). Laterality-right (R); left (L); central (C).

icant interaction between incentive valence and value $\left(F_{(4,88)}=\right.$ $0.356, p=0.84)$. These results suggest that, at least in the context of this experiment, the ventral striatum is not encoding a signed incentive value. Instead, these neural responses are more consistent with a role for the ventral striatum in encoding the degree of a participants' motivation for performing a subsequent motor action, regardless of this action being to acquire monetary gain or avoid monetary loss.

Ventral striatal responses during the motor task

In the gain condition, we found that activity in the ventral striatum switched from an increasing response with increasing prospective gains during the incentive presentation phase to a decreasing response with increasing prospective gains during the motor task (Fig. 3B). That is, the larger the potential gain the participant was working to attain, the greater the degree of deactivation observed in the ventral striatum. To rule out the possibility that these neural responses were confounded by differences in behavioral performance between successful and unsuccessful trials, we focused our analysis only on those trials in which participants ultimately succeeded. However, as in our previous study, the result of decreased neural activity at the time of motor performance also held for trials in which participants were unsuccessful.

In the loss condition, contrary to our initial hypothesis but consistent with the pattern of results observed during the incentive presentation phase, activity in the ventral striatum rapidly switched from activation in response to increasing prospective loss at the time of incentive presentation to deactivation during 
A

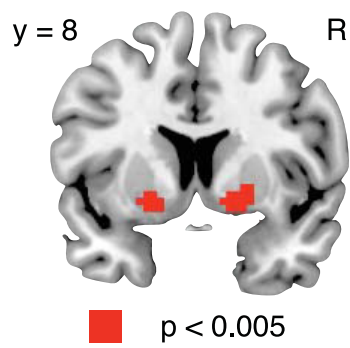

B

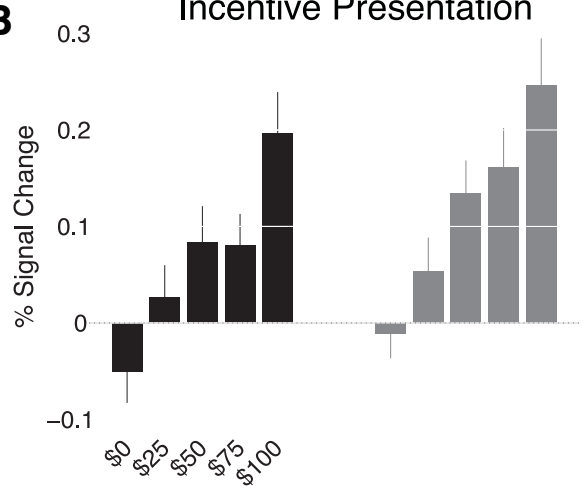

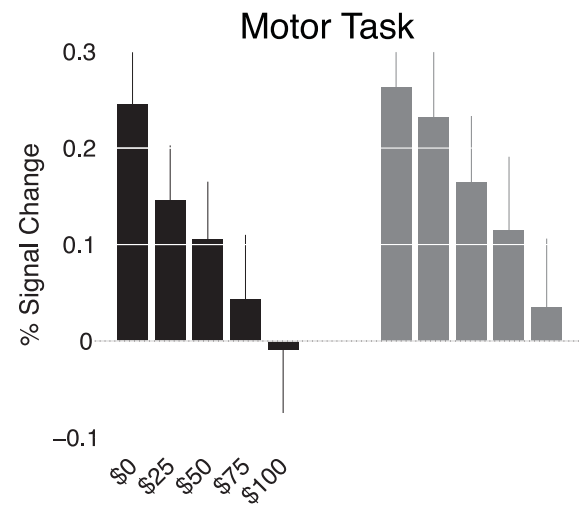

Loss

Gain
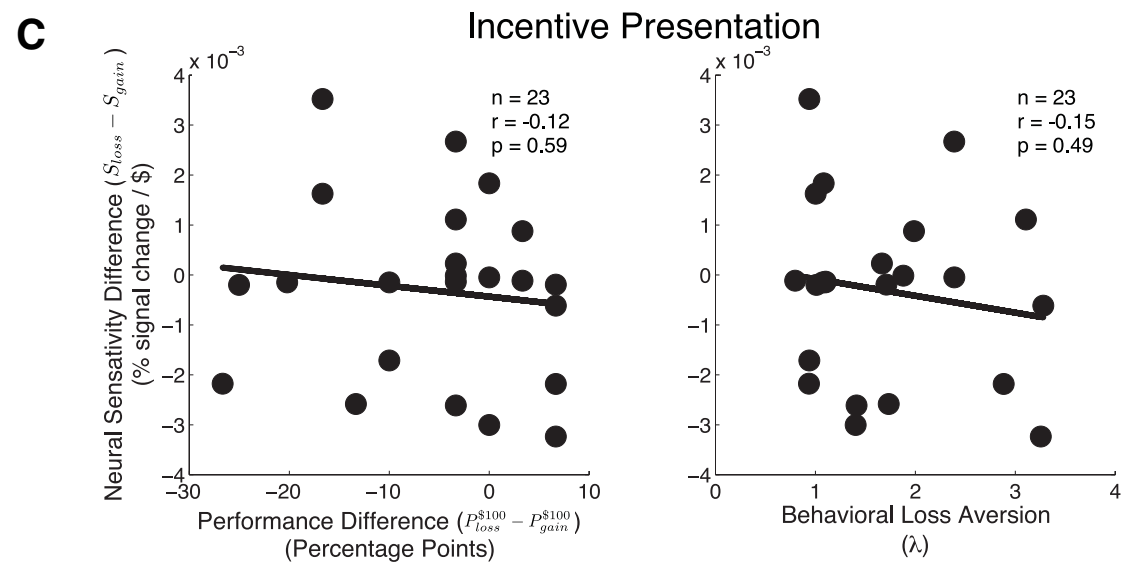

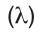

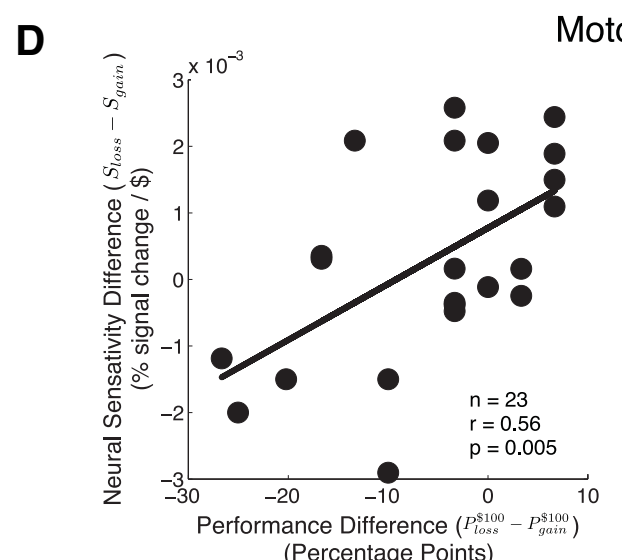

Motor Task

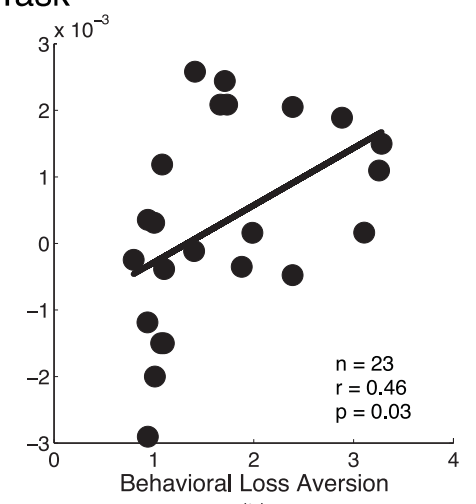

( $\lambda)$

Figure 3. fMRI results. A, A common region of ventral striatum was implicated during execution of the motor task in the loss and gain conditions (significant at $p<0.05$, small-volume corrected in an a priori ventral striatum ROI). $\boldsymbol{B}$, Activity in the ventral striatum was negatively correlated with the magnitude of incentive at the time of the motor task. This pattern of activation held for both the loss and gain conditions. $C$, At the time of incentive presentation, plots of the correlations between the difference in neural sensitivity between the loss and gain conditions and the difference in performance between the $\$ 100$ loss and gain conditions (left) and behavioral loss aversion (right). $\boldsymbol{D}$, At the time of the motor task, plots of the correlations between the difference in neural sensitivity between the loss and gain conditions and the difference in performance between the $\$ 100$ loss and gain conditions (left) and behavioral loss aversion (right).

the motor phase (Fig. 3B). We found a significant main effect of incentive during the motor phase $\left(F_{(4,88)}=18.36, p<0.0001\right)$. There was neither a significant effect of valance $\left(F_{(1,22)}=3.04\right.$, $p=0.10)$ nor a significant interaction between incentive valence and value $\left(F_{(4,88)}=2.00, p=0.10\right)$.

Overall, the ventral striatum showed the same pattern of simple effects during the gain and loss conditions: increasing activity scaling with the magnitude of potential gain/loss (at the time of incentive presentation), followed by a rapid deactivation correlating with the magnitude of potential gain/loss (at the time of the motor task).

Relationship between ventral striatal activity, motor performance, and loss aversion

We examined between-participant relationships across neural sensitivity to incentive, behavioral performance at the highest 
A
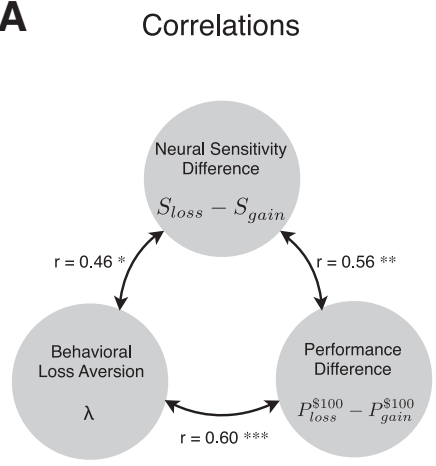

B

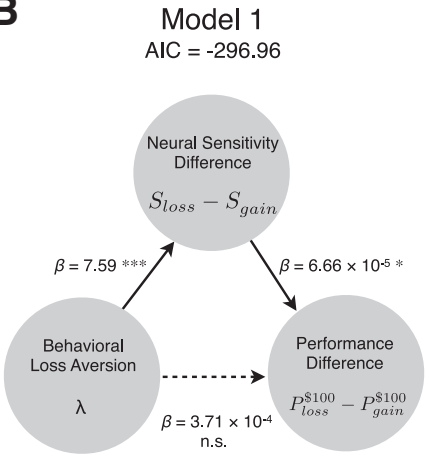

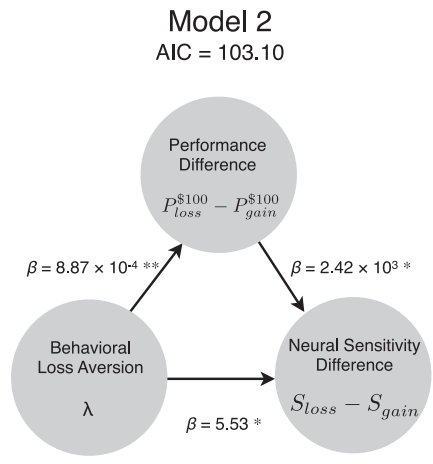

Figure 4. Mediation analysis. $\boldsymbol{A}$, The three variables assessed using mediation analysis: behavioral loss aversion $\lambda$, difference in neural sensitivity between losses and gains $S_{\text {loss }}-S_{\text {gain }}$ and difference in performance between losses and gains, $P_{\text {loss }}^{\$ 100}-P_{\text {gain }}^{\$ 100}$ (at the $\$ 100$ incentive level). The numbers next to the double-headed arrows are coefficients of correlations between the variables. Regression analyses (illustrated in Figs. $2 B, 3 D$ ) established correlations between participants' behavioral loss aversion, differences in performance, and neural sensitivity for potential losses and gains. $\boldsymbol{B}$, Model 1 illustrates the mediation analysis, and Model 2 illustrates the reverse mediation analysis used to rule out model misspecification. ${ }^{*} p<0.05 ;{ }^{*} p<$ $0.01 ;{ }^{* * *} p<0.005$.

level of gain/loss, and behavioral loss aversion. Neural sensitivity to incentive was defined as the slope of the relationship between BOLD percentage signal change and incentive level. These analyses allowed us to explore how participants' ventral striatal signals influenced behavioral performance and how these responses were related to participants' subjective valuation of losses and gains.

In the gain condition, at the time of task execution, the degree of deactivation in response to increasing incentives was correlated with the degree of choking for large incentives $(r=0.51, p=$ $0.006)$. Also, as reported previously, no correlation was found between activity during the incentive phase and performance $(r=0.12, p=0.60)$. We next examined these same relationships for the loss condition. We observed a similar trend between decreased neural sensitivity and performance decrements at the highest levels of prospective loss, during the motor phase $(r=$ $0.40, p=0.03$ ). As expected, the same tests performed during the incentive phase of the loss condition did not reach significance $(r=0.01, p=0.96)$.

Next we tested for an interaction between differences in neural sensitivity, $S_{\text {loss }}-S_{\text {gain }}$, and performance $P_{\text {loss }}^{\$ 100}-P_{\text {gain }}^{\$ 100}$ in the loss and gain conditions. These difference measures compliment the measure of behavioral loss aversion. Although behavioral loss aversion is a measure of how losses are valued with respect to equal magnitude gains, $S_{\text {loss }}-S_{\text {gain }}$ is a measure of ventral striatal activity in response to prospective losses compared with prospective gains [a measure analogous to the measure of "neural loss aversion" of a previous study (Tom et al., 2007)], and $P_{\text {loss }}^{\$ 100}-$ $P_{\text {gain }}^{\$ 100}$ is a measure of performance in the $-\$ 100$ condition compared with the $+\$ 100$ condition.

We found that those participants with more striatal deactivation during the motor task in the loss condition relative to the gain condition performed worse for large losses than for large gains ( $r=0.56, p=0.005$; Fig. $3 D$, left). Moreover, participants loss aversion was predictive of these differences in neural sensitivity ( $r=0.46, p=0.03$; Fig. $3 D$, right): those participants who were more loss averse deactivated more in the gain condition, whereas those who were less loss averse deactivated more in the loss condition. None of these relationships were significant at the time of incentive presentation $(r=-0.12, p=0.59 ; r=-0.15$, $p=0.49$; Fig. $3 C)$.
Causal influences of behavioral loss aversion and neural responses on performance

Because behavioral loss aversion and differential performance responses to losses and gains are correlated (Fig. $4 A$ ) and both of these variables are correlated with the differences in neural sensitivity for losses and gains, we investigated the hypothesis that neural sensitivity has a causal influence on loss aversion-related decrements in motor performance. To test this hypothesis, we used mediation analysis, a form of linear modeling in which correlations observed in the data are explained by assuming that a specific set of causal influences exist among the variables (Judd and Kenny, 1981). This analysis alone does not establish causality but identifies which causal hypotheses (models) are best fit for the data. We fit two different models to the between-participant data and compared their goodness of fit (Fig. 4B). Both models assumed that behavioral loss aversion influenced participants' differences in neural sensitivity and performance for incentives offered as a potential loss or gain. Model 1 assumed that behavioral loss aversion influenced differences in neural sensitivity for potential losses and gains and that neural sensitivity (the mediating variable) influenced differences in performance. Model 2 was a reverse mediation model with performance serving as the mediator between loss aversion and performance; this is an alternatively viable possibility because neural sensitivity measures were acquired in the same time window as measures of performance and could thus arise as a result of behavioral performance.

The best-fitting model was considered to be the one with the smallest AIC, a measure of goodness of fit. Figure $4 B$ shows that Model 1 (AIC $=-296.96$ ) had the lowest AIC measure compared with Model 2 (AIC $=103.10)$. In Model 1, behavioral loss aversion had a significant effect on differences in neural sensitivity between losses and gains $(\beta=7.59, t=3.41, p=0.006)$. When behavioral loss aversion and difference in neural sensitivity were simultaneity modeled as predictors of performance, loss aversion no longer significantly predicted performance $(\beta=$ $\left.3.71 \times 10^{-4}, t=0.98, p=0.31\right)$, whereas neural sensitivity remained significant in the model $\left(\beta=6.66 \times 10^{-5}, t=2.20\right.$, $p=0.04)$. This reduction in the direct relationship between loss aversion and performance was significant (95\% confidence interval, $3.06 \times 10^{-5}$ to $1.15 \times 10^{-3} ; p<0.05$, as tested by a biascorrected bootstrapping procedure based on 10,000 resamples). The reverse mediation analysis (Model 2) ruled out model mis- 
A

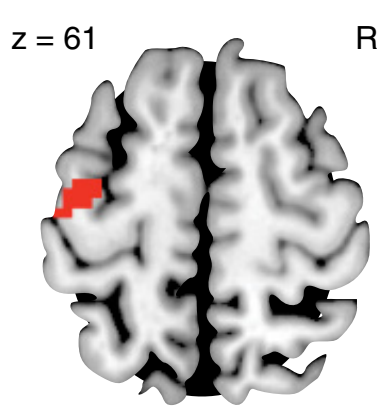

$\mathrm{p}<0.005$
B

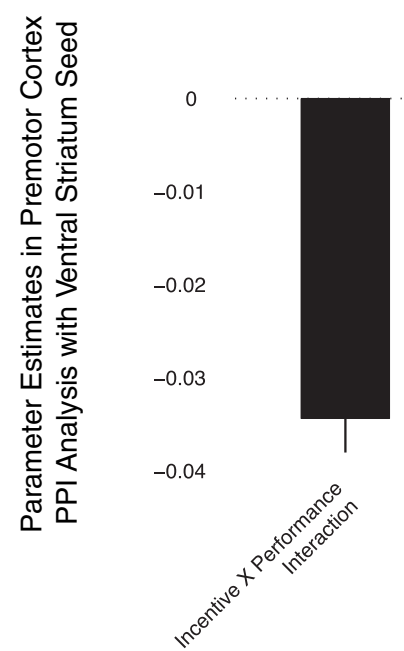

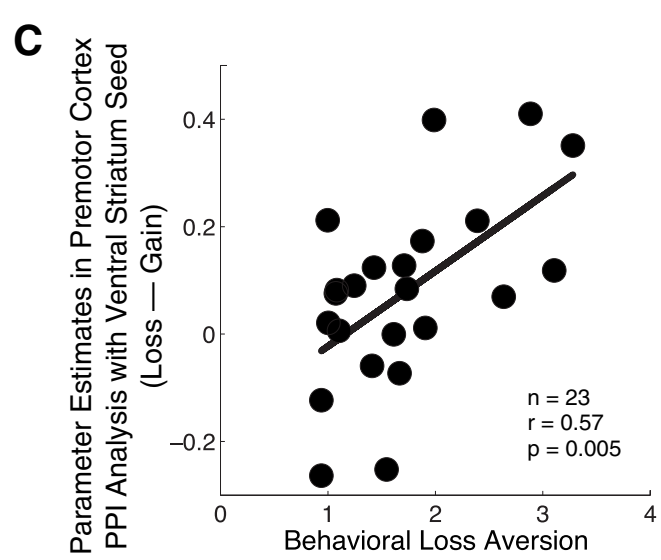

$(\lambda)$

Figure 5. PPI. $A, B$, Functional coupling between the ventral striatum and premotor cortex was significantly decreased during large incentive trials (for both gains and losses) in which performance was diminished. C, Plots of correlations between participants' loss aversion and their difference in ventral striatum-premotor coupling between the loss and gain conditions. Participants with low loss aversion had decreased ventral striatum-motor coupling in the loss condition compared with the gain condition; those with high loss aversion had decreased ventral striatum-premotor coupling in the gain condition compared with the loss condition.

specification and indicated only partial mediation by performance $(\beta=5.53, t=2.91, p=0.01)$.

Together, the strong support for Model 1 and very weak support for Model 2 indicate a parsimonious interpretation of our findings: that manifestations of loss aversion hinder behavioral performance through the influence of ventral striatal activity on motor performance.

Functional coupling between the ventral striatum and premotor cortex

Finally, to address how the ventral striatum influences motor performance, we tested whether it showed a functional coupling to regions of motor cortex likely to be involved in implementing motor control during task execution. To achieve this, we preformed a PPI using the ventral striatum as a seed. This analysis revealed a robust modulation of connectivity between the ventral striatum and a region of the premotor cortex as a function of performance and incentive level: the strength of connectivity was weaker in both the loss and gain conditions on trials for large incentives in which performance was diminished (Fig. $5 \mathrm{~A}, \mathrm{~B}$; Table 5). Furthermore, the differential strength of connectivity between these two regions for losses compared with gains was predicted by the extent of a participant's behavioral loss aversion $(r=0.57, p=0.005$; Fig. $5 C)$. Participants that were more loss

averse had decreased connectivity between the ventral striatum and the premotor cortex in the gain domain compared with the loss domain. The results of this PPI analysis support the hypothesis that the ventral striatum acts to influence activity in the premotor cortex, a region integral in the planning and guidance of motor actions and ultimately orchestrating behavioral performance.

\section{Alternative neural accounts of performance}

We also examined the possibility that choking results from conflict signals generated in the anterior cingulate cortex (ACC) at the time of motor performance, when incentives could be reframed. To test for an ACC role in choking, we constructed a contrast between the difference in activation during unsuccessful and successful trials, at incentive levels in which participants showed choking behavior (for losses and gains together) at the time of motor performance. The incentive levels were extracted separately for each participant by determining the incentive level resulting in peak performance and examining trials at all incentive levels above that peak incentive level. If conflict were the underlying mechanism resulting in the choking phenomenon, we would expect to see more activity in unsuccessful compared with successful trials. However, a whole-brain analysis found no brain areas that survived a $p<0.005$ threshold.

In an additional test of the conflict hypothesis, we extracted parameter estimates from the ACC at the time of motor performance in the abovementioned contrast. We generated a $10 \mathrm{~mm}$ spherical ROI centered on coordinates $(3,19,35)$ obtained from a meta-analysis localizing ACC activity in tasks involving manual response conflict (Barch et al., 2001). Using reaction time data from the behavioral loss aversion task, we also constructed an independent behavioral conflict measure related to encoding of loss aversion. This conflict score was determined for each subject by taking the difference in their reaction times at the extremes of difference in expected value (i.e., when decisions are most certain and choice is made most rapidly) and reaction times at the point of indifference (i.e., when choices are at chance and decisions are made least rapidly). This measure captures how decision conflict is encoded during simple behavioral choices related to gains and losses. We did not find a significant correlation between parameter estimates extracted from ACC and measures of task performance and behavioral choice conflict measures $(n=23, r=-0.13, p=0.55)$.

It is also possible that the insula is encoding an aversive emotional state that leads to increased susceptibility to choking. To test this possibility, we constructed a contrast similar to that described above, except we examined the gain and loss conditions separately in case the insula responds differently depending on incentive valence. If insular cortex activity is driving choking, we would expect more activity in the insula on unsuccessful com- 
Table 5. Regions with a significant functional coupling between ventral striatum as modulated by performance and incentive ( $p<0.001$, uncorrected)

\begin{tabular}{|c|c|c|c|c|c|}
\hline \multirow[b]{2}{*}{ Brain region } & \multirow[b]{2}{*}{ Laterality } & \multicolumn{3}{|c|}{$\begin{array}{l}\text { Peak Talairach } \\
\text { coordinates (mm) }\end{array}$} & \multirow{2}{*}{$\begin{array}{l}\text { Peak } \\
t \text { value }\end{array}$} \\
\hline & & $x$ & $y$ & $z$ & \\
\hline Premotor cortex ${ }^{*}$ & $\mathrm{~L}$ & -30 & -4 & 61 & 4.29 \\
\hline Supplementary motor area & $\mathrm{L}$ & -24 & -10 & 49 & 5.27 \\
\hline Parietal cortex & $\mathrm{L}$ & -60 & -22 & 38 & 4.20 \\
\hline Occipital cortex & $\mathrm{L}$ & -27 & -82 & -2 & 4.48 \\
\hline
\end{tabular}

Statistically significant activations are those found in a priori regions of interest (familywise error, ${ }^{*} p<0.05$ ) and those regions that survive whole-brain correction for multiple comparisons (at $\left.{ }^{*} p<0.05\right)$. Laterality - right $(\mathrm{R})$; left (L); central (C).

pared with successful trials. Whole-brain analyses for both the loss and gain conditions found no brain areas that survived a $p<$ 0.005 threshold.

In an additional test of this insula effect, we examined average parameter estimates from the bilateral anterior insula for the abovementioned contrasts. We generated a $10 \mathrm{~mm}$ spherical ROI centered on coordinates from left $(-36,16,2)$ and right $(24,20$, -8 ) anterior insula obtained from a meta-analysis localizing activity in contrasts examining the difference between monetary loss and gain anticipation (Knutson and Greer, 2008). We used the parameter estimates from these regions to examine correlations between the insular activity in the aversion contrast and behavioral loss aversion. Neither of these correlations reached significance (losses: $n=23, r=0.08, p=0.72$; gains: $n=23, r=$ $-0.02, p=0.92$ ), suggesting that our neural data does not support this potential explanation.

\section{Discussion}

Here we show that, in the face of increasing incentives, the framing of a skilled task can profoundly influence an individual's susceptibility to choking effects. Our behavioral findings are consistent with previous reports that large prospective monetary gains can elicit choking effects (Ariely et al., 2009; Mobbs et al., 2009; Chib et al., 2012). We further show that large prospective losses can induce similar choking responses and that individual differences in loss aversion have a distinct effect on choking for prospective losses compared with gains. Our neural results build on previous findings implicating the ventral striatum in responding when incentives are first offered (Knutson et al., 2001a,b; Seymour et al., 2007; Cooper and Knutson, 2008) but go beyond these studies by illustrating that ventral striatal responses for gains and losses directly influence behavioral performance. In so doing, we demonstrate that manifestations of loss aversion hinder behavioral performance through the influence of ventral striatal activity on motor cortical activity.

We observed differential choking responses for prospective losses compared with gains. Remarkably, as predicted by our initial hypothesis, we found that individuals of high loss aversion were less susceptible to choking effects for prospective losses compared with gains. Unexpectedly, we also found that behavioral performance in the loss condition varied across the continuum of behavioral loss aversion, such that individuals of low loss aversion were more susceptible to choking effects for prospective losses compared with gains. Thus, the manner in which a task is framed appears to have a profound influence on susceptibility to incentive-related choking effects.

One possible interpretation of the finding that low loss averse participants are more susceptible to choking effects in the loss condition compared with the gain condition is that these individuals may have greater behavioral sensitivity to gains compared with losses; in contrast, high loss averse participants might have greater behavioral sensitivity to losses than gains. In such a framework, when switching from a loss to a gain frame between the initial cue presentation and the motor task, low loss averse participants may react more strongly to the reframed prospective gain than high loss averse participants. Such high reactivity to a reframed potential gain could in turn elicit arousal and/or appetitive pavlovian responses that subsequently interfere with motor performance. The implication of this proposal would be that choking effects are not generated exclusively by the prospect of a loss [as hypothesized in our previous study (Chib et al., 2012)] but instead are elicited by prospective outcomes that induce strong affective reactions, regardless of whether those outcomes are losses or gains. In the context of our experiment, the loss aversion measure captures this differential sensitivity and can predict whether choking effects are likely to manifest in response to losses or gains.

If these results generalize to other types of tasks and incentives, there could be important implications for developing new behavioral techniques to overcome choking under pressure. Tailoring the framing of tasks and incentive mechanisms in terms of potential gain or loss, depending on a person's behavioral loss aversion, could potentially mitigate decreases in performance for large incentives. Indeed, choking effects have been reported across a variety of domains, such as mathematical problem solving (Beilock and Carr, 2001, 2005; Beilock et al., 2004; Beilock, 2008), tasks involving fluid intelligence (Gimming et al., 2006), and athletics (Jordet and Hartman, 2008; Apesteguia and Palacios, 2010; Pope and Schweitzer, 2011). However, before such specific applications can be considered in the context of task framing and incentive design, additional work is necessary to establish the generality of these findings.

The present results also provide important new insights into the neural mechanisms underlying basic incentive and motivational processing, as well as in accounting for how choking effects are manifested at the neural level. Although we replicated a large amount of previous literature (including our own previous study) showing that the ventral striatum encodes prospective monetary gains at the time of incentive presentation (Knutson et al., 2001a,b; Yacubian et al., 2006; Tom et al., 2007; Cooper and Knutson, 2008; Chib et al., 2012), we also found that the ventral striatum responded in a very similar manner to increasing prospective losses at the time of incentive presentation. That is, the ventral striatum showed increasing activations proportional to the magnitude of both prospective gains and prospective losses. This type of response profile has been reported widely in the literature as reflecting motivation, arousal, or "salience" (Knutson et al., 2001a,b; Cooper and Knutson, 2008). Although increasing ventral striatal activity in response to cues predicting aversive outcomes such as pain (Jensen et al., 2003; Seymour et al., 2005; Delgado et al., 2008) and aversive or nonpreferred tastes (O'Doherty et al., 2006) have also been reported, in the case of monetary aversive outcomes (i.e., losses), the literature has been much less consistent (Brooks and Berns, 2013); some studies reported decreases in response to cues predicting monetary losses (Delgado et al., 2000; Yacubian et al., 2006; Tom et al., 2007), whereas others reported increases (Seymour et al., 2007; Cooper and Knutson, 2008). One possibility arising from these different findings is that the responses of the ventral striatum to aversive outcomes may be very sensitive to the context in which those outcomes are presented (Seymour et al., 2007).

At the time of the motor task, consistent with our previous results for the gain condition (Chib et al., 2012), we found that 
the ventral striatum showed a switch in its activity profile such that it deactivated in proportion to the magnitude of the incentive offered. The slope of the deactivation in response to increasing incentives was associated with behavioral susceptibility to choking: the steeper the deactivation, the greater the susceptibility to choking. Furthermore, this deactivation was also correlated with individuals' behavioral loss aversion, such that more loss averse individuals showed greater deactivation in response to increasing losses. Moreover, the degree of choking also correlated directly with behavioral loss aversion.

We initially hypothesized that during the loss condition we would see the opposite pattern of effects in the ventral striatum: an initial decrease in activity during incentive presentation, consistent with loss encoding, followed by a switch to increasing activity during the motor phase, associated with a reframing a prospective loss. Clearly this hypothesis was not confirmed. Instead we saw the same striatal response as that observed in the gain condition: increasing activity for prospective losses at the time of loss presentation and decreasing activity with increasing prospective losses at the time of the motor task. These findings suggest that the switching activity pattern in the striatum is not indicative of a change in incentive framing between gain and loss or vice versa. Instead, the results support a role for the ventral striatum, during the motor task, in influencing behavioral performance regardless of whether the task involves prospective gains or losses. The difference in activity in the ventral striatum in response to losses versus gains was correlated with behavioral differences in susceptibility to choking for losses versus gains across individuals; effects that were also correlated with individuals' behavioral loss aversion. Together, these results suggest a very general role for the ventral striatum in influencing interactions between motivation and behavioral performance. Deactivation in the ventral striatum during performance of the motor task appears to be directly related to behavioral performance; the greater the extent of deactivation, the greater the probability that behavioral performance will be impaired.

Further supporting these conclusions was a mediation analysis showing that ventral striatal activity mediated the effects of behavioral loss aversion on performance at the highest levels of gain and loss. This mediation suggests that the ventral striatum is not merely indirectly correlated with performance through its reflection of loss aversion but instead plays a critical role in moderating behavioral performance itself. Furthermore, in a PPI analysis, we showed that functional connectivity between the ventral striatum and motor cortical areas changes when participants are performing the task for large prospective losses and gains. In particular, we observed a decrease in coupling between the ventral striatum and premotor cortex during trials in which individuals choke compared with when they do not. These results provide insight into how the ventral striatum acts to influence motor performance via connectivity with the premotor cortex.

Together, our results place the ventral striatum at the center of the interface between motivation and performance and begin to shed light on how the ventral striatum comes to influence neuromotor control. However, the precise computations that bring to bear the influence of the ventral striatum on the motor system are still unclear. One possibility, in line with a burgeoning literature implicating this region in mediating the influence of pavlovian cues on instrumental performance (Bray et al., 2008; Talmi et al., 2008; Balleine and O'Doherty, 2010), is that pavlovian skeletomotor responses are engaged as a function of incentive cues (both appetitive and aversive), and, in turn, these responses in- teract with neural systems involved in mediating instrumental behavioral performance. The ventral striatum may play a critical role in implementing or controlling such skeletomotor pavlovian responses.

\section{References}

Apesteguia J, Palacios I (2010) Psychological pressure in competitive environments: evidence from a randomized natural experiment. Am Econ Rev 100:2548-2564. CrossRef

Ariely D, Gneezy U, Loewenstein G, Mazar N (2009) Large stakes and big mistakes. Rev Econ Studies 76:451-469. CrossRef

Balleine BW, O'Doherty JP (2010) Human and rodent homologies in action control: corticostriatal determinants of goal-directed and habitual action. Neuropsychopharmacology 35:48-69. CrossRef Medline

Barch DM, Braver TS, Akbudak E, Conturo T, Ollinger J, Snyder A (2001) Anterior cingulate cortex and response conflict: effects of response modality and processing domain. Cereb Cortex 11:837-848. CrossRef Medline

Baumeister RF (1984) Choking under pressure-self-consciousness and paradoxical effects of incentives on skillful performance. J Pers Soc Psychol 46:610-620. CrossRef Medline

Beilock SL (2008) Math performance in stressful situations. Curr Dir Psychol Sci 17:339-343. CrossRef

Beilock SL, Carr TH (2001) On the fragility of skilled performance: what governs chocking under pressure? J Exp Psychol Gen 130:701-725. Medline

Beilock SL, Carr TH (2005) When high-powered people fail working memory and "choking under pressure" in math. Psychol Sci 16:101-105. CrossRef Medline

Beilock SL, Kulp CA, Holt LE, Carr TH (2004) More on the fragility of performance: choking under pressure in mathematical problem solving. J Exp Psychol Gen 133:584-600. CrossRef Medline

Bray S, Rangel A, Shimojo S, Balleine B, O’Doherty JP (2008) The neural mechanisms underlying the influence of pavlovian cues on human decision making. J Neurosci 28:5861-5866. CrossRef Medline

Brooks AM, Berns GS (2013) Aversive stimuli and loss in the mesocorticolimbic dopamine system. Trends Cogn Sci 17:281-286. CrossRef Medline

Chib VS, De Martino B, Shimojo S, O’Doherty JP (2012) Neural mechanisms underlying paradoxical performance for monetary incentives are driven by loss aversion. Neuron 74:582-594. CrossRef Medline

Cooper JC, Knutson B (2008) Valence and salience contribute to nucleus accumbens activation. Neuroimage 39:538-547. CrossRef Medline

Deichmann R, Gottfried JA, Hutton C, Turner R (2003) Optimized EPI for fMRI studies of the orbitofrontal cortex. Neuroimage 19:430-441. CrossRef Medline

Delgado MR, Nystrom LE, Fissell C, Noll DC, Fiez JA (2000) Tracking the hemodynamic responses to reward and punishment in the striatum. J Neurophysiol 84:3072-3077. Medline

Delgado MR, Li J, Schiller D, Phelps EA (2008) The role of striatum in aversive learning and aversive prediction errors. Philos Trans R Soc Lond B Biol Sci 363:3787-3800. CrossRef Medline

Friston KJ, Buechel C, Fink GR, Morris J, Rolls E, Dolan RJ (1997) Psychophysiological and modulatory interactions in neuroimaging. Neuroimage 6:218-229. CrossRef Medline

Frydman C, Camerer C, Bossaerts P, Rangel A (2011) MAOA-L carriers are better at making optimal financial decisions under risk. Proc Biol Sci 278:2053-2059. CrossRef Medline

Gimming D, Huguet P, Caverni JP, Cury F (2006) Choking under pressure and working memory capacity: when performance pressure reduces fluid intelligence. Psychonom Bull Rev 13:1005-1010. CrossRef

Jensen J, McIntosh AR, Crawley AP, Mikulis DJ, Remington G, Kapur S (2003) Direct activation of the ventral striatum in anticipation of aversive stimuli. Neuron 40:1251-1257. CrossRef Medline

Jordet G, Hartman E (2008) Avoidance motivation and choking under pressure in soccer penalty shootouts. J Sport Exerc Psychol [Erratum (2009) 31:128-129].

Judd CM, Kenny DA (1981) Process analysis: estimating mediation in treatment evaluations. Eval Rev 5:602-619. CrossRef

Knutson B, Greer S (2008) Anticipatory affect: neural correlates and consequences for choice. Philos Trans R Soc B Biol Sci 383:3771-3786. CrossRef

Knutson B, Adams CM, Fong GW, Hommer D (2001a) Anticipation of 
increasing monetary reward selectively recruits nucleus accumbens. J Neurosci 21:RC159(1-5). Medline

Knutson B, Fong GW, Adams CM, Varner JL, Hommer D (2001b) Dissociation of reward anticipation and outcome with event-related fRMI. Neuroreport 12:3683-3687. CrossRef Medline

Mayka MA, Corcos DM, Leurgans SE, Vaillancourt DE (2006) Threedimensional locations and boundaries of motor and premotor cortices as defined by functional brain imaging: a meta-analysis. Neuroimage 31: 1453-1474. CrossRef Medline

Mobbs D, Hassabis D, Seymour B, Marchant JL, Weiskopf N, Dolan RJ, Frith CD (2009) Choking on the money: reward-based performance decrements are associated with midbrain activity. Psychol Sci 20:955-962. CrossRef Medline

O’Doherty JP, Buchanan TW, Seymour B, Dolan RJ (2006) Predictive neural coding of reward preference involves dissociable responses in human ventral midbrain and ventral striatum. Neuron 49:157-166. CrossRef Medline

Pope DG, Schweitzer ME (2011) Is Tiger Woods loss averse? Persistent bias in the face of experience, competition, and high stakes. Am Econ Rev 101:129-157. CrossRef

Seymour B, O’Doherty JP, Koltzenburg M, Wiech K, Frackowiak R, Friston K,
Dolan R (2005) Opponent appetitive-aversive neural processes underlie predictive learning of pain relief. Nat Neurosci 8:1234-1240. CrossRef Medline

Seymour B, Daw N, Dayan P, Singer T, Dolan R (2007) Differential encoding of losses and gains in the human striatum. J Neurosci 27:4826-4831. CrossRef Medline

Sokol-Hessner P, Hsu M, Curley NG, Delgado MR, Camerer CF, Phelps EA (2009) Thinking like a trader selectively reduces individuals' loss aversion. Proc Natl Acad Sci U S A 106:5035-5040. CrossRef Medline

Talmi D, Seymour B, Dayan P, Dolan RJ (2008) Human pavlovianinstrumental transfer. J Neurosci 28:360-368. CrossRef Medline

Tom SM, Fox CR, Trepel C, Poldrack RA (2007) The neural basis of loss aversion in decision-making under risk. Science 315:515-518. CrossRef Medline

Tverskey A, Kahneman D (1992) Advances in prospect theory: cumulative representation of uncertainty. J Risk Ucertain 5:297-323. CrossRef

Yacubian J, Gläscher J, Schroeder K, Sommer T, Braus DF, Büchel C (2006) Dissociable systems for gain-and loss-related value predictions and errors of predictions in the human brain. J Neurosci 26:9530-9537. CrossRef Medline 